\title{
Endotherapy for Complications of Pancreatitis: Ready for Prime Time
}

\author{
Todd H. Baron, MD, FACP, Division of Gastroenterology and Hepatology, Mayo Clinic College of Medicine, Rochester, Minnesota
}

[See related article pp. 119 - 123]

\author{
REPRINT REQUESTS: \\ Todd H. Baron, MD, FACP \\ Division of Gastroenterology \\ and Hepatology \\ Mayo Clinic College of Medicine \\ 200 First Street SW, Charlton 8 \\ Rochester, MN 55905 \\ Telephone: 507-266-6931 \\ Fax: 507-266-3939 \\ Email: baron.todd@mayo.edu
}

\section{KEYWORDS:}

Pancreatitis; Endoscopy;

Pancreatic pseudocyst
Acute and chronic pancreatitis may lead to local complications as a result of ductal injury. In the setting of acute pancreatitis the main pancreatic duct or its side branches may be disrupted. These ductal injuries can be minimal and associated with leakage of only fluid, or severe with necrosis of a large amount of pancreatic parenchyma along with the duct lying in the same area. ${ }^{1,2}$ The sequela of these disruptions is the development of pancreatic pseudocysts or organized necrotic pancreatic collections. When these types of collections become symptomatic (e.g., abdominal pain, pressure on surrounding structures with resultant gastric outlet obstruction, infection, and ascites) drainage is usually required. Chronic pancreatitis can produce scarring and obstruction of the main pancreatic duct, frequently in association with obstructing calculi. The pancreatic duct upstream to the obstruction continues to secrete pancreatic juice. The subsequent pressure may produce a ductal blowout (leak) with pseudocyst formation, pancreatic ascites or pancreatic fistula. ${ }^{2}$ Ductal obstruction can also produce acute pancreatitis in the obstructed pancreatic segment and can be acute in chronic pancreatitis. Finally, worsening of chronic abdominal pain may also occur. All these complications of chronic pancreatitis may also require drainage.

In this issue of Clinical Medicine \& Research, Musana et al. ${ }^{3}$ describe successful endoscopic treatment of pancreatic pseudocysts tracking within the mediastinum, producing a pancreaticopleural fistula and cardiac compression. Since the pseudocysts were caused by the mechanism of pancreatic ductal obstruction with leak, successful resolution was achieved by extraction of the obstructing pancreatic duct stone.

Traditional management of pancreatic fluid collections, such as the one presented by Musana et al. ${ }^{3}$ has been medical ${ }^{4}$ and/or surgical, $, 5,6$ and occasionally radiological (percutaneous). ${ }^{7-9}$ Although endoscopic therapy for this complication has been previously described, ${ }^{10-12}$ surgery remains the gold standard for interventional therapy of pancreatic disease by which other therapies are judged. This is because endoscopic therapy (endoscopic retrograde cholangiopancreatography) is the "new kid" on the block for the treatment of pancreatic disease, second to surgery, the only available non-medical therapy that has proven itself. ${ }^{13}$ Well, the new kid has been around now for over 20 years. The first successful endoscopic drainage therapy for 
pancreatic pseudocysts using transgastric and transduodenal stent placement was described by Kozarek ${ }^{14}$ in 1985 . Since that time endoscopic therapy for pancreatic disease has included drainage of acute and chronic pseudocysts and pancreatic necrosis, ${ }^{15}$ treatment of pancreatico-cutaneous fistulae following surgical and percutaneous drainage, and treatment of ductal disruptions from trauma. ${ }^{13}$ On the front of pain therapy, by relieving obstruction of the main pancreatic duct in the setting of chronic pancreatitis, endoscopic therapy has fared well in selected patients. ${ }^{13}$ Truly, pancreatic endotherapy has come a long way, but has it been completely embraced as frontline therapy for pancreatic disease in which an intervention is necessary? I believe it has not, partly because of the lack of education of physicians across many disciplines and because it has not been proven in head-to-head comparisons with surgery, the gold standard.

Is it necessary for endoscopic therapy to undergo comparative trials to prove itself once and for all as an accepted alternative to surgery? Endoscopic comparative studies for patients with complicated pancreatic disease are difficult to perform for a variety of reasons: the diseases are not so common as to allow ready enrollment without the need for randomized trials; the populations are heterogeneous and endpoints may be difficult to define; experienced pancreatic endoscopists are relatively uncommon and collaboration is needed from their surgical colleagues to participate and to enroll patients; funding is not readily available for these studies; and it may be unethical to enroll poor-operative patients into a study where they may be randomized to surgery. Finally, from my own experience, patients may be reluctant to enter a study when endoscopic therapy seems reasonable and avoids major surgery. Despite all these issues, pancreatic endotherapy will continue to make its way into mainstream treatment because of publications, such as the one by Musana et al. ${ }^{3}$ in this issue of Clinical Medicine \& Research, though it is important to note that pancreatic endotherapy is technically demanding, potentially dangerous, and should be restricted to high-volume centers with options for an interdisciplinary team approach. Well-designed, retrospective and prospective case series of endoscopic, radiological, and surgical techniques using accepted nomenclature ${ }^{16}$ will allow us to make meaningful comparisons between disciplines and prove that endotherapy for complications of pancreatitis is effective and a solid surgical alternative.

It's 9 p.m. and your patient needs mechanical intervention of their pancreas. Do you know where your therapeutic endoscopist is?

\section{REFERENCES}

1. Baron TH, Morgan DE. The diagnosis and management of fluid collections associated with pancreatitis. Am J Med 1997;102:555-563.

2. Andrén-Sandberg $\AA$, Dervenis C. Pancreatic pseudocysts in the 21 st century. Part I: classification, pathophysiology, anatomic considerations and treatment. JOP 2004;5:8-24.
3. Musana K, Yale SH, Abdulkarum A, Rall CJ. Successful endoscopic treatment of mediastinal pseudocysts. Clin Med Res 2004;2:119-123.

4. Yasuda H, Ino Y, Igarashi H, Arita Y, Nakamuta M, Sumii T, Nawata H. A case of pancreatic pleural effusion and mediastinal pancreatic pseudocyst: management by a somatostatin analogue octreotide. Pancreas 1999;19:410-412.

5. Banks PA, McLellan PA, Gerzof SG, Splaine EF, Lintz RM, Brown ND. Mediastinal pancreatic pseudocyst. Dig Dis Sci 1984;29:664-668.

6. Beauchamp RD, Winsett M, Nealon WH. Operative strategies in the management of mediastinal pancreatic pseudocyst. Surgery 1989;106:567-570.

7. Wittich GR, Karnel F, Schurawitzki H, Jantsch H. Percutaneous drainage of mediastinal pseudocysts. Radiology 1988;167:51-53.

8. Aabakken L, Chittom P, McKay DC, Uflacker R, Wilson FA. Percutaneous drainage of a mediastinal pancreatic pseudocyst: a paraspinal, extrapleural CT-guided approach. J Vasc Interv Radiol 1997;8:283-285.

9. Tan MH, Kirk G, Archibold P, Kennedy P, Regan MC. Cardiac compromise due to a pancreatic mediastinal pseudocyst. Eur J Gastroenterol Hepatol 2002;14:1279-1282.

10. Kim DJ, Chung HW, Gham CW, Na HG, Park SW, Lee SJ, Chung JP, Song SY, Chung JB, Kang JK. A case of complete resolution of mediastinal pseudocyst and pleural effusion by endoscopic stenting of pancreatic duct. Yonsei Med J 2003;44:727-731.

11. Mallavarapu R, Habib TH, Elton E, Goldberg MJ. Resolution of mediastinal pancreatic pseudocysts with transpapillary stent placement. Gastrointest Endosc 2001;53:367-370.

12. Mohl W, Moser C, Kramann B, Zeuzem S, Stallmach A. Endoscopic transhiatal drainage of a mediastinal pancreatic pseudocyst. Endoscopy 2004;36:467.

13. Neuhaus H. Therapeutic pancreatic endoscopy. Endoscopy 2004;36:8-16.

14. Kozarek RA, Brayko CM, Harlan J, Sanowski RA, Cintora I, Kovac A. Endoscopic drainage of pancreatic pseudocysts. Gastrointest Endosc 1985;31:322-327.

15. Baron TH. Endoscopic drainage of pancreatic fluid collections and pancreatic necrosis. Gastrointest Endosc Clin N Am 2003;13:743-764.

16. Baron TH. Defined nomenclature of pancreatic fluid collections. Gastrointest Endosc 2003;57:287-288. 